\title{
Léon Bloy, Louis Montchal et Henriette L'Huillier, Correspondance 1884-1906
}

\section{Maria Emanuela Raffi}

\section{(2) OpenEdition}

\section{Journals}

\section{Edizione digitale}

URL: https://journals.openedition.org/studifrancesi/3178

DOI: 10.4000/studifrancesi.3178

ISSN: 2421-5856

\section{Editore}

Rosenberg \& Sellier

\section{Edizione cartacea}

Data di pubblicazione: 1 juillet 2013

Paginazione: 481

ISSN: 0039-2944

\section{Notizia bibliografica digitale}

Maria Emanuela Raffi, «Léon Bloy, Louis Montchal et Henriette L'Huillier, Correspondance 1884-1906»,

Studi Francesi [Online], 170 (LVII | II) | 2013, online dal 30 novembre 2015, consultato il 01 février 2023. URL: http://journals.openedition.org/studifrancesi/3178; DOI: https://doi.org/10.4000/studifrancesi. 3178

Questo documento è stato generato automaticamente il 1 février 2023.

\section{cc) (ㅇ) $\ominus$}

Creative Commons - Attribuzione - Non commerciale - Non opere derivate 4.0 Internazionale - CC BYNC-ND 4.0

https://creativecommons.org/licenses/by-nc-nd/4.0/ 


\title{
Léon Bloy, Louis Montchal et Henriette L'Huillier, Correspondance
} 1884-1906

\author{
Maria Emanuela Raffi
}

\section{NOTIZIA}

LÉON BLOY, LOUIS MONTCHAL ET HENRIETTE L'HUILLIER, Correspondance 1884-1906, édition critique par Gaëlle GUYOT-ROUGE, Paris, Classiques Garnier, 2012, pp. 709.

1 Questa raccolta di 286 lettere, alcune delle quali in estratto, costituisce l'insieme completo della corrispondenza fra Léon Bloy e Louis e Adèle Montchal, arricchito rispetto alla precedente edizione del 1947 (Lettres aux Montchal) di alcune lettere a Bloy da parte dei Montchal e di Henriette l'Huillier e di una lettera di Bloy pubblicata al di fuori del volume del 1947. Nell'ampia e dettagliata «Préface» che apre l'edizione, Gaëlle Guyot-Rouge illustra la nascita della corrispondenza, iniziata da Louis Montchal, bibliotecario a Ginevra, nel 1884, come reazione alla lettura dei Propos d'un entrepreneur de démolitions. Pur nello squilibrio evidente e riconosciuto dei due interlocutori principali, con Bloy che impedisce sistematicamente a Montchal di cimentarsi nella scrittura, ciò che caratterizza il rapporto è una profonda comprensione umana, che si fa spesso compassione. «De cette compassion reciproque, l'espace fictif de la lettre est l'unique et puissant creuset» scrive l'A. che tuttavia rileva, nella coralità incrociata della corrispondenza estesa alla moglie di Montchal, Adèle, e all'amica di lui, Henriette l'Huillier, una diversità di toni che porterà nel tempo alla luce l'ambiguità delle situazioni. La corrispondenza si incrocia inoltre, all'esterno, con altre complesse relazioni di Bloy: quella con Huysmans e quella con Johanne Molbech che diverrà sua moglie nel 1890.

2 Dal punto di vista più strettamente letterario, la corrispondenza accompagna la nascita del primo romanzo di Bloy, Le Désespéré, nel 1884 e ne segue la realizzazione fino al 
1887, fornendo anche personaggi e situazioni al testo narrativo: «ce qui se vit et s'éprouve dans l'espace épistolaire - scrive Gaëlle Guyot-Rouge - est très vite absorbé par le roman: Montchal, qui sera de façon symptomatique, le dédicataire du Désespéré, en devient un des personnages [...]». Ma anche il rafforzarsi dei legami con il simbolismo, attraverso Huysmans e Villiers de l'Isle-Adam, passano per gli scambi epistolari con il bibliotecario di Ginevra, così come la polemica con i firmatari del «Manifeste des cinq»e la genesi de La Femme pauvre e di Un dilemme, fino al definitivo dissolversi della corrispondenza negli esiti opposti che caratterizzano, dopo gli inizi del Novecento, i due interlocutori. All'inverso della realizzazione affettiva e letteraria di Bloy, il destino di erranza ed esilio di Montchal si chiude nell'isolamento anche da colui di cui si era tante volte dichiarato il «dévoué et tendre serviteur et ami». 